\title{
A Study on the Application of Reading-to-Write Approach in Senior High English Writing Classes
}

\author{
Li Hao \\ College of Teacher Education, Nanjing Normal University, Nanjing, China
}

\section{Email address:}

827575070@qq.com

\section{To cite this article:}

Li Hao. A Study on the Application of Reading-to-Write Approach in Senior High English Writing Classes. International Journal of Secondary Education. Vol. 7, No. 2, 2019, pp. 33-36. doi: 10.11648/j.ijsedu.20190702.12

Received: April 23, 2019; Accepted: May 29, 2019; Published: June 13, 2019

\begin{abstract}
Reading-to-write approach, an increasingly popular English teaching model in China, refers to the integration of reading and writing together, through which learners can accumulate various writing skills from reading materials, such as useful vocabulary, sentence patterns, and text structures. And then they are required to write in the form of imitation, rewriting, continuation and so on. As a result, these two processes are both emphasized and mutual promoted at the same time. The present paper explored the current situation of senior high English writing classes in China and the effects of this newly developed model combined with group cooperation and peer assessment. Students from a high school in Nanjing were invited as research participants. Original data collected from questionnaires, interviews and exams was carefully analyzed. The results showed that the reading-to-write approach was feasible and effective, and exerted positive influence on students' English writing interest, writing ability, and their sense of self-efficacy to some degree. Meanwhile, it was revealed that interactions between the teacher and students, together with peer assessments, were beneficial to create a harmonious atmosphere in class, as well as decreased the anxiety of writing. Therefore, students' enthusiasm was stimulated greatly. English teachers can apply this method while teaching so that students' language proficiency will be improved effectively. Group cooperation should also be taken into consideration.
\end{abstract}

Keywords: English Teaching in Senior High, Writing Approach, Reading-to-Write

\section{Introduction}

English writing is an important way to examine students' overall language proficiency. However, traditional teaching methods in China tend to neglect the importance of writing, and consider reading and writing as two separate parts. Many teachers even lay undue emphasis on language points.

Reading and writing are supposed to be closely relevant, for reading is a way of information input, through which students can accumulate language materials and text structures, while writing is a process of internalization and output. By combining input and output, students accumulate necessary knowledge about a certain topic. Through a series of domestic and international research [1-6], it is evident that reading-to-write approach is conductive to enhance students' writing ability. However, few studies encourage students to finish writing in group and allow them to polish others' work. Regarding this, the present study tries to supplement this model, and come up with pedagogical advice as well.

\section{Literature Review}

\subsection{Definition of Reading-to-Write Approach}

For a long time, many researchers have focused on studies of reading and writing separately. Widdowson (1978:120) initially put forward the concept of integrating reading and writing. He believed that learners can master reading skills through writing and vice versa [7]. Blanton (1992) created a new teaching model initially, in which students were required to write a short passage related to the text they had read and then shared their opinions with other group members [8]. This is the basic pattern of reading-to-write approach and subsequent studies inherit this model.

Different definitions were given, but there are some common points. Reading-to-write approach emphasizes both input and output. Reading can not only provide language knowledge, but also help students realize the relationship 
between language structures and functions. Students can obtain writing strategies from reading, such as necessary words, phrases, sentence patterns and text structures. As a result, students can formulate their own knowledge hierarchy based on different topics.

\subsection{The Relation Between Reading and Writing}

With whole language teaching approach bubbling to the surface in the 1970s, more and more researchers realized that reading and writing were two closely connected processes. Reading-to-write approach advanced by leaps and bounds. Input Hypothesis put forward by Krashen (1985) [9] and Output Hypothesis by Swain (1985) [10] are two major theoretical bases that guide this method.

Reading and writing are triggered by similar cognitive construction mechanism. Kucer (1987) argued that they have common cognitive foundations in four aspects [11]. First, learners predicted the meaning of knowledge and constructed the meaning of passages in two processes. Second, the written language mechanism stored information in a database, while users extracted information from the same one. Third, the similar procedure was used when readers and writers transferred knowledge into texts. Fourth, two processes showed common processing ability. Also, they have logical connectivity. Xie Weina (1994) further proposed that they imitated each other [12]. While reading, you pretended to be the writer to guess the intention. While writing, you pretended to be the reader for understanding better.

However, the previous studies ignored the importance of group work and peer assessment in senior high English classes. Kim and his partner (2017) conducted a study and found that learning-oriented language assessment could promote the effects of reading-to-write approach, but it was the teacher who gave advice [13]. The present study combined group cooperation and peer assessment, in which students finished writing in group and evaluated others' work, aiming at reducing anxiety, mobilizing students' various senses and skills and as well as improving their writing ability.

\section{Method}

\subsection{Research Questions}

The present study aims to explore the following three questions based on reading-to-write approach combined with group cooperation and peer assessment: (1) Its influence on senior high school students' interest in English writing. (2) Its influence on senior high school students' English writing ability. (3) Its influence on senior high school students' self-efficacy towards English writing.

\subsection{Research Instruments and Participants}

Research instruments employed in this study were questionnaires, interviews and exams. 32 students from a school in Nanjing took part in the study.

As for questionnaires, two kinds were used at two times. The first one with 15 questions was used before reading-to-write classes, with a view to investigate current situation of English writing. The second questionnaire with 9 questions was to investigate general attitudes towards reading-to-write lessons. 140 Copies of the first questionnaire were distributed and 128 were recovered. 32 Copies of the second questionnaire were sent out and 32 were recovered. As for interviews, six students of different levels were invited to talk about their feelings about the present English writing learning and their feelings towards reading-to-write approach. Two parallel classes were involved in the experiments. One was taught by reading-to-write approach and the other was by the traditional method. Considering their midterm exams, their English levels were similar before the experiment.

\subsection{Research Procedures}

Three months were spent to trying out the reading-to-write approach combined with group cooperation and peer assessment. Apart from traditional arrangements in reading classes, the author also designed a writing lesson based on related topic in the next class.

Take one teaching period as an example. The reading text was a trip to lost civilizations. In the next class, students were asked to write a piece of diary in group to describe their travel in historical sites. Students talked about their experience in group first. Four students were in a group and they had to finish one composition together. Each of them not only need write one part of the passage, but also polish others' work, so each paragraph was read at least three times. Afterwards, they shared their writing with whole class. Comments were made by teacher and other classmates.

\section{Results}

\subsection{Current Situation of English Writing}

Generally speaking, the current situation of English writing was not so satisfied based on the questionnaires. Although the majority of students considered English writing as moderately difficult, few of them showed interest in writing. And their articles were usually evaluated by their teachers instead of peers, while $22 \%$ wished to increase interactions during writing. It was obvious that combining reading-to-write approach with group cooperation and peer assessment meets students' need.

In order to investigate students' awareness of combing reading and writing, the first questionnaire included questions like 'Do you usually write down and use good expressions in text books or reading passages?' Nearly $65 \%$ didn't pay attention to good expressions in reading materials. And $48 \%$ students said that their teachers assigned reading tasks to assist writing, which was a good phenomenon. What's more, only $4 \%$ students usually communicated with their teachers and friends during writing,

\subsection{Influence of Reading-to-Write Approach on English Writing}

\subsubsection{Influence on Students' Interest}

According to the first questionnaire, about $38 \%$ students 
were interested in English writing to some extent, while unexpectedly almost half students showed no interest. As to the second questionnaire, $82 \%$ students deemed that they were more interested in English writing after taking reading-to-write lessons. This figure manifested that students' interest can be arisen by reducing difficulty and anxiety through different methods, such as preparatory reading and pair work. More than half students expressed their willingness to improve writing through daily accumulation, indicating that students gradually realized the benefits of this approach and tried to accept it.

Table 1. Contents of the first questionnaire for students.

\begin{tabular}{lllll}
\hline Contents & $\begin{array}{l}\text { Very } \\
\text { interested }\end{array}$ & interested & $\begin{array}{l}\text { Not } \\
\text { interested }\end{array}$ & indifferent \\
\hline $\begin{array}{l}\text { Do you interested in } \\
\text { English writing? }\end{array}$ & $3 \%$ & $38 \%$ & $44 \%$ & $16 \%$ \\
\hline
\end{tabular}

Also, a student who attended interview mentioned that his favourite part is writing with friends. He feels more comfortable. When reading others' work, he could see many familiar expressions and he wanted to use them next time.

\subsubsection{Influence on Students' Writing Ability}

Senior high students have already memorized many words, but they can't use them handily. There is no doubt that they can greatly enhance their writing ability with the help of reading text.

Before applying this approach, only $28 \%$ students noticed good expressions while reading. The figure increased dramatically after study, reaching a total of $68 \%$. However, according to interviews and observations, students are apt to imitate passages mainly in textbooks instead of other materials. Learning English is a long period, students should pay more attention to everything in the course of learning.

Table 2. The T test of two classes'scores after the experiment.

\begin{tabular}{llllll}
\hline & N & M & SD & T & P \\
\hline Control Group & 30 & 12.77 & 1.30 & 2.629 & 0.011 \\
Experimental Group & 30 & 13.70 & 1.44 & & \\
\hline
\end{tabular}

It can be seen from the $\mathrm{T}$ test that there is significant difference in achievement $(\mathrm{t}=2.63, \mathrm{P}=0.011, \mathrm{P}<0.05)$ between the experimental group and the control group. The average value of the experimental group (13.70) was significantly higher than that of the control group (12.77), validating that this approach can enhance students' writing ability to some extent.

\subsubsection{Influence on Students' Writing Self-Efficacy}

Self-efficacy is the degree of one's belief or estimate in his ability to complete tasks and reach goals. According to the interviews and questionnaires, it was clear that students were more confident and willing to apply this approach in daily learning. But there were still students reluctant to use this method. We should take students' interest and average levels into account. From the first questionnaire, almost half students were not interested in English writing. It would inevitably take plenty of time and efforts to alter students' stereotype about English writing.

Table 3. The contents of the second questionnaire for Students.

\begin{tabular}{|c|c|c|c|c|c|}
\hline Content & Totally agree & Agree & uncertain & disagree & Strongly disagree \\
\hline $\begin{array}{l}\text { Reading-to-write approach arises my interest in } \\
\text { writing and make me more confident. }\end{array}$ & $32 \%$ & $50 \%$ & $12 \%$ & $6 \%$ & $0 \%$ \\
\hline
\end{tabular}

\section{Discussion}

Many factors contribute to the situation of current English writing learning in China. First, teachers are inclined to neglect the training of writing in teaching since $55 \%$ of college entrance examination is related to reading, while writing only takes up $20 \%$. Therefore, it seems that training is not proportional to results. Second, the problem is also triggered by teachers' inefficient feedback. Some teachers only focus on students' vocabulary or grammatical mistakes. In turn, students don't know how to polish their writing and improve the structure step by step. So group cooperation and peer assessment are useful ways.

In addition, based on questionnaires, interviews and exams, it is completely feasible and effective to carry out reading-to-write approach combined with group cooperation and peer assessment in senior high. Even those underachievers can make their own sentences. The effects of this approach are not limited to English writing. Students' attitude and behavior also go through significant changes. Compared with traditional classes, it can improve students' interest from the following aspects. First of all, it helps students overcome fear and anxiety of writing, which has been proved by many studies related to group cooperation and peer assessment [14-15]. Second, students have more chance to communicate with classmates, thus creating a harmonious atmosphere. Third, it makes students to realize that writing needs appreciation instead of mere translation and recitation. With the help of writing materials, their vocabulary use, sentence structures as well as text organizations improve a lot. Therefore, their writing ability and self-efficacy are also promoted.

\section{Conclusion}

In order to cultivate students' awareness of integrating reading and writing, proper strategies need to be applied. Great importance should be attached to reading process, especially thinking training and genre analysis. Additionally, teachers should adjust the way of feedback. They need to affirm the flash points of students' writing and make suggestions on the framework. With regard to small mistakes, such as vocabulary, it is advisable to encourage students to 
revise by themselves or classmates, through which they can learn from others' advantages and shortcomings.

Although reading-to-write approach combined with group cooperation and peer assessment has been proved to be effective, there are still limitations concerning the scope and the period of this study. The research sample is relatively small and data collection is not enough. Also, the study only lasts three month. The present study only serves as a preliminary of reading-to-write approach. In order to get a profound understanding of this method, more influencing factors ought to be taken into consideration.

\section{References}

[1] Tsang, W. K. (1996). Comparing the effects of reading and writing on writing performance [J]. Applied Linguistics 17 (2): 208-233.

[2] Mermelstein, L. (2005). Reading/ Writing Connections in the K-12 Classroom: Find the Clarity and then Blur the Lines [M]. Person Schweiz Ag.

[3] Yang Yonglin \& Dong Yuzhen. (2010). Reading promotes writing, Writing promotes reading--A New Exploration of Teaching Mode from the Perspective of Experiencing English [J], Chinese Foreign Language (1): 13-2.

[4] Cai Yifan \& Wang Wenqin. (2015). Reflections on the Teaching Model of Combination of Reading and Writing in Senior High School English [J]. Foreign Language Teaching and Learning in Middle School (5): 3-8.

[5] Soltani, A., \& Kheirzadeh, S. (2017). Exploring EFL students' use of writing strategies and their attitudes towards reading-to-write and writing-only tasks $[\mathrm{J}]$. Journal of Language \& Linguistic Studies 13(2): 535-560.
[6] Doubet, K. J., \& Southall, G. (2018). Integrating reading and writing instruction in middle and high school: the role of professional development in shaping teacher perceptions and practices. Literacy Research \& Instruction 57(5): 1-21.

[7] Widdowson, H. (1978). Teaching Language as Communication [M]. London: Oxford University Press.

[8] Blanton. (1992). A Holistic Approach to college ESL, Integrating language and Content [J]. ELT Journal 46 (3):1-24.

[9] Krashen, S. D. (1985). The Input Hypothesis: Issues and Implications [M]. London, Longman.

[10] Swain, M. (1985). Communicative competence: Some roles of comprehensible input and comprehensible output in it in its development. In S. M. Gass \& C. G. Madden (eds.), Input in second language acquisition, Newbury House Publishers, New York, 235-253.

[11] Kucer, S. B. (1987). The Cognitive Base of Reading and Writing [A]. In J.Squire (ed.), The dynamics of Language Learning. Urbana: National Conference in Research in English. 27-51.

[12] Xie Weina. (1994). On the integration of reading and writing [J]. Foreign Language Teaching (4): 50-52.

[13] Kim, A. Y., \& Kim, H. J. (2017). The ffectiveness of instructor feedback for learning-oriented language assessment: using an integrated reading-to-write task for english for academic purposes. Assessing Writing 32: 57-71.

[14] Oludipe, D., \& Awokoy, J. O. (2010). Effect of cooperative learning teaching strategy on the reduction of students' anxiety for learning chemistry. Journal of Turkish Science Education $7(1): 30-36$

[15] Erdogan, O. (2017). The effect of cooperative writing activities on writing anxieties of prospective primary school teachers $[\mathrm{J}]$. International Journal of Research in Education and Science 3 (2): $560-570$. 